Article

\title{
Stabilization of Iron (Micro)Particles with Polyhydroxybutyrate for In Situ Remediation Applications
}

\author{
Laura Chronopoulou ${ }^{1}$, Cleofe Palocci ${ }^{1}$, Francesco Valentino ${ }^{1}$, Ida Pettiti ${ }^{1}$, \\ Stanisław Wacławek ${ }^{2}$, Miroslav Černík ${ }^{2}$ and Marco Petrangeli Papini ${ }^{1, *}$ \\ 1 Department of Chemistry, Università degli Studi di Roma La Sapienza, Piazzale Aldo Moro 5, Rome 00185, \\ Italy; laura.chronopoulou@uniroma1.it (L.C.); cleofe.palocci@uniroma1.it (C.P.); \\ francesco.valentino@uniroma1.it (F.V.); ida.pettiti@uniroma1.it (I.P.) \\ 2 Institute for Nanomaterials, Advanced Technologies and Innovation, Technical University of Liberec, \\ Studentská 1402/2, 46117 Liberec 1, Czech Republic; stanislaw.waclawek@tul.cz (S.W.); \\ miroslav.cernik@tul.cz (M.C.) \\ * Correspondence: marco.petrangelipapini@uniroma1.it; Tel.: +39-06-4991-3646 \\ Academic Editor: Raed Abu-Reziq \\ Received: 4 October 2016; Accepted: 6 December 2016; Published: 9 December 2016
}

\begin{abstract}
Groundwater is an extremely important resource that may, however, contain a variety of toxic and bioaccumulative contaminants. Traditional "Pump and Treat" technologies for treating contaminated groundwater are no longer time- or cost-effective; therefore, new technologies are needed. In this work, we synthesized core-shell materials of micrometric dimensions based on the interaction of iron particles (the core) and fermentable biopolymers such as polyhydroxybutyrate ( $\mathrm{PHB}$, the surrounding shell) to be used in permeable reactive barriers for the removal of chlorinated pollutants from contaminated groundwater. The materials were prepared by precipitation techniques that allowed stable preparations to be obtained, whose chemico-physical properties were thoroughly characterized by scanning electron microscopy, porosimetry, Fourier transform infrared spectroscopy (FTIR), thermogravimetric analyses, disc centrifuge analysis, and dynamic light scattering. The properties of the prepared materials are very promising, and may enhance the performance of permeable reactive barriers towards chlorinated compounds.
\end{abstract}

Keywords: colloidal stability; zero-valent iron; polyhydroxybutyrate; biopolymer

\section{Introduction}

In many parts of Europe-especially where surface water is of limited supply or poor quality-groundwater is a fundamental resource. It is used as the main source of drinking water by many European cities and towns, and it is a major source for irrigation in most European countries. Unfortunately, a variety of toxic and bioaccumulating contaminants have been detected in groundwater, including a wide spectrum of chlorinated hydrocarbons, halogenated aliphatic hydrocarbons, pesticides, pharmaceuticals, and metals [1]. The contamination of groundwater by persistent organic contaminants can have long-term adverse effects on both human health and the environment [2]. In accordance with the European Union (EU) Groundwater Directive (2006/118/EC) on the protection of groundwater against chemical pollution, the Member States will have to prevent or limit the input of emerging contaminants to groundwater, and tailor their regulation to the specific circumstances [3].

One of the most largely applied approaches in groundwater remediation is based on the so called "Pump and Treat" (P \& T) technology, in which the whole contaminated plume is intercepted by a hydraulic barrier, and the extracted water is treated on-site before being discharged, typically in 
a superficial body [4]. Depending on the spectrum and complexity of the contamination, a groundwater treatment may consist of a single cleanup method, but often requires several treatment units for the removal of different types of contaminants or high concentrations of a single contaminant $[5,6]$. In both cases, the treatment plant often includes units based on columns packed with sorbent (usually activated carbon) for the removal of dissolved concentrations of hydrophobic organic contaminants. One of the main drawbacks of this approach is the cost associated with the treatment combined with the length of the intervention, ranging from a few years to several decades, depending on the contaminant concentration, plume size, type of contaminant source, and hydrogeological setting. This often makes P\&T unsustainable from an economical point of view.

During the last two decades, permeable reactive barriers (PRBs) have been established as robust alternatives to traditional pump and treat approaches for groundwater remediation [7-9]. PRBs-a passive in situ treatment of groundwater contaminated by organic and inorganic contaminants-are trenches or gates excavated in the subsoil to intercept the contaminated plume, filled with a granular (permeable) reactive material (e.g., zero-valent iron, activated carbon, zeolites, compost, etc., or their combination) chosen to treat the contaminated groundwater passing through it under a natural hydraulic gradient $[10,11]$. Depending on the specific case, pollutants may be thus trapped in situ by sorption or converted into non-hazardous compounds by chemical or biological routes.

Granular zero-valent iron (ZVI) is the most commonly used filling material, thanks to its capability to degrade a wide range of organic contaminants, and reducing and immobilizing harmful metal ions [12]. Usually, ZVI is successfully used for the remediation of groundwater contaminated by chlorinated aliphatic compounds through a series of dechlorination reactions until the formation of nontoxic species, such as ethene and ethane $[13,14]$. Available iron-based materials that are also used in large-scale applications may have various shapes, sizes, and surface properties, depending on the manufacturing sources. As a consequence, their reductive powers vary in a wide spectrum. For example, many commercial sources of ZVI currently used to construct PRBs have ferric oxides on their particle surfaces. As water penetrates the iron particle surface oxides, anaerobic corrosion begins with a consequent hydrogen evolution that is of considerable importance in developing PRB remediation technology [15]. Different methods have been proposed to provide a good reference for the quantitative assessment of the reactivity of metallic reducing agents of environmental interest, including ZVIs. The most relevant examples include the use of concentrated Fe(III) solution [16], tri-iodide [17], and methylene blue [18].

To date, ZVI has been applied in the construction of hundreds of PRBs worldwide, particularly for the degradation of chlorinated solvents $[19,20]$. However, PRB-ZVI technology is still affected by some operational problems, the main one most likely being the long-term decrease in performance due to loss of ZVI reactivity and and/or porosity [21]. In fact, the alkaline $\mathrm{pH}(8-9)$ and the presence of ferrous and ferric ions within the barrier (both due to ZVI corrosion) lead to the precipitation of minerals which—depending on the groundwater chemical composition—can form a passive layer on the surface of the iron that hampers the electron transfer processes and reduces iron reactivity. Additionally, iron precipitation could cause pore occlusion, resulting in a greater seepage velocity, thus reducing the treatment effectiveness (due to a residence time decrease). Moreover, some compounds (i.e., chloromethane 1,2-dichloroethane, dichloromethane) are not chemically reduced in the presence of ZVI [22]. Most of these compounds can, however, be degraded via biological reductive dechlorination, provided that specific microorganisms and available electron donors are present [23]. In this regard, the most common strategy to stimulate natural biological activity is to inject essential nutrients and electron donors, thereby maximizing the metabolism of the existing microbiome. The commercial products usually employed are soluble molasses or easily degradable organic compounds (i.e., lactate, polylactate, etc.), with the major drawback being the need for their continuous delivery in the groundwater for a lengthy period (long periods are usually required to achieve the remediation goals by using this approach). To overcome these limitations, in recent years, several researchers have shown a growing interest in developing composite materials obtained by the combination of 
consolidated chemically reactive media with a slow-releasing carbon source (i.e., guar gum, cellulose, starch) to extend treatment to recalcitrant compounds and/or to enhance microbial activity in a synergistic reaction [24-27]. In this context, polyhydroxybutyrate (PHB) could be a valuable carbon source. PHB can be efficiently fermented by different microorganisms under anaerobic conditions into well-defined and predictable fermentation products, such as volatile fatty acids and molecular hydrogen, which may be used as an electron donor by dechlorinating bacteria. Moreover, PHB can be produced by bacteria starting from mixed substrates or even wastewaters [28]. In a recent study, we developed nano-ZVI/PHB composites that showed interesting properties in preliminary reactivity studies towards perchloroethene (PCE) $[29,30]$.

The aim of this work was to synthesize and accurately characterize the chemical/physical properties of core-shell materials of micrometric dimensions based on the interaction of iron particles (the core) and biopolymers such as polyhydroxyalkanoates (the surrounding shell) for the removal of chlorinated pollutants from contaminated groundwater. In particular, fermentable polymers such as PHB were used to couple with ZVI. In this work, we used commercially available ZVI (whose cost is significantly lower than that of nanoscale ZVI—approximately $0.7 \$ / \mathrm{kg}$ vs. $120 \$ / \mathrm{kg}$ ), and this would be very advantageous for large-scale applications. This work was entirely dedicated to the development and characterization of innovative ZVI-PHB composites. In the future, such materials have the potential to enhance the performance of PRBs towards chlorinated compounds through the combined action of ZVI and dechlorinating microorganisms, mediated by the use of PHB as a slow-releasing electron donor.

\section{Materials and Methods}

\subsection{Materials}

Chloroform ( $\geq 99 \%$ ) was purchased from Sigma (St. Louis, MO, USA) and used as received. ZVI was kindly provided by Connelly-GPM Inc. (Chicago, IL, USA) for investigation purposes. Before use, it was sieved, and the fraction with dimensions smaller than $45 \mu \mathrm{m}$ was selected. Polyhydroxybutyrate (PHB, Biomer ${ }^{\circledR}$ P209) was purchased from Biomer (Krailing, Germany). In order to reduce its crystallinity, before its use, PHB powder was melted on a heated surface and immediately frozen.

\subsection{Preparation of ZVI-PHB Complexes}

Thermally pretreated PHB was dissolved in chloroform at a concentration of $0.25 \mathrm{mg} / \mathrm{mL}$. ZVI samples were dispersed in water through sonication for $15 \mathrm{~min}$. A selected amount of PHB solution was then mixed with the ZVI aqueous dispersion and sonicated for another $15 \mathrm{~min}$ (PHB/ZVI $2: 1,1: 1$, or $1: 2 w / w)$. Chloroform was then eliminated by placing the mixture in a rotary evaporator (Labtech Srl, Sorisole, Italy) until the complete disappearance of the organic phase. The ZVI-PHB complex was recovered from the aqueous phase by filtration.

\subsection{Scanning Electron Microscopy}

For microscopy studies, samples were deposited on mica supports and analyzed using an Auriga 405 (ZEISS, Oberkochen, Germany) microscope, operating at low extracting voltage (1.5-4 kV) and current ( $7.5 \mu \mathrm{m}$ aperture) in order to reduce the significant charging of the substrate and avoid radiation damages and artifacts.

\subsection{Attenuated Total Reflectance Fourier Transform Infrared Spectroscopy (ATR-FTIR) Analysis}

Attenuated total reflectance Fourier transform infrared spectroscopy (ATR-FTIR) spectra were obtained on a spectrophotometer (NICOLET IZ10, Thermo Scientific, Waltham, MA, USA) equipped with a single reflection signal angle $45^{\circ}$ horizontal ATR accessory. The spectra were obtained with a resolution of $4 \mathrm{~cm}^{-1}$ at $4000-400 \mathrm{~cm}^{-1}$ using a germanium ATR crystal. 


\subsection{Textural Analysis}

Surface area, Brunauer-Emmett-Teller (BET) multipoint method [31], and textural analysis were obtained by $\mathrm{N}_{2}$ adsorption/desorption measurements at the liquid nitrogen temperature $\left(-196^{\circ} \mathrm{C}\right)$ using a 3-Flex 3500 analyzer (Micromeritics, Norcross, GA, USA). The samples were pre-treated under vacuum at $80-90{ }^{\circ} \mathrm{C}$ for $3 \mathrm{~h}$. The pores distribution was determined from the adsorption curve by the Barret-Joyner-Halenda (BJH) method [32]. The total pore volume was determined by the rule of Gurvitsch.

\subsection{Thermogravimetric Analysis (TGA) Measurements}

Thermal stability and composition of the PHB and ZVI-PHB complexes were determined using TGA/SDTA851e apparatus (Mettler Toledo, Columbus, OH, USA). The experimental atmosphere was nitrogen at a flow rate of $20 \mathrm{~mL} / \mathrm{min}$. The sample was heated from $30{ }^{\circ} \mathrm{C}$ to $700{ }^{\circ} \mathrm{C}$.

\subsection{Disc Centrifuge Analysis}

The centrifugal particle sedimentation technique (CPS Disc Centrifuge, DC24000UHR, CPS Instruments Inc., Prairieville, LA, USA) was used for particle size distribution analysis. Measurements were made at a disc rotation speed of $4800 \mathrm{rpm}$, and the particle sedimentation was carried out in a $8 \%-24 \%(w / w)$ sucrose density gradient. Prior to each sample measurement, the instrument was calibrated using a $1400 \mathrm{~nm}$ PVC nanosphere standard (CPS Instruments Inc., Prairieville, LA, USA).

\subsection{Zeta Potential Measurements}

The zeta potential values were determined in freshly prepared suspensions with a Zetasizer ZS (Malvern Instruments Ltd., Malvern, UK). Each measurement was performed in sequences of ten runs with autocorrelation functions set at $10 \mathrm{~s}$. The zeta potential of each sample was obtained from the average of three measurements.

\section{Results and Discussion}

\subsection{Preparation and Morphological Characterization of ZVI-PHB Complexes}

ZVI was combined with PHB by using an operatively simple procedure based on the precipitation of the polymer from an organic phase in the presence of an aqueous dispersion of ZVI. Different $\mathrm{ZVI} / \mathrm{PHB}$ ratios $(2: 1,1: 1$ and 1:2 $w / w)$ were tested. We first investigated the morphology of the ZVI sample used for the preparation of ZVI-PHB complexes by using SEM (scanning electron microscopy) microscopy, which revealed a highly irregular and microporous morphology (Figure 1A). With the same technique, we then analyzed ZVI-PHB samples prepared with different ZVI/PHB ratios. Representative images are reported in Figure 1B-D. It can be seen that the presence of PHB seems to have altered the surface of ZVI. This is more evident for the ZVI-PHB sample prepared with the highest quantity of PHB (ZVI/PHB ratio of 1:2 w/w), where the polymer seems to have formed a film on the Fe surface (Figure 1D). All further studies were therefore conducted on ZVI-PHB complexes with a ZVI/PHB ratio of 1:2. 

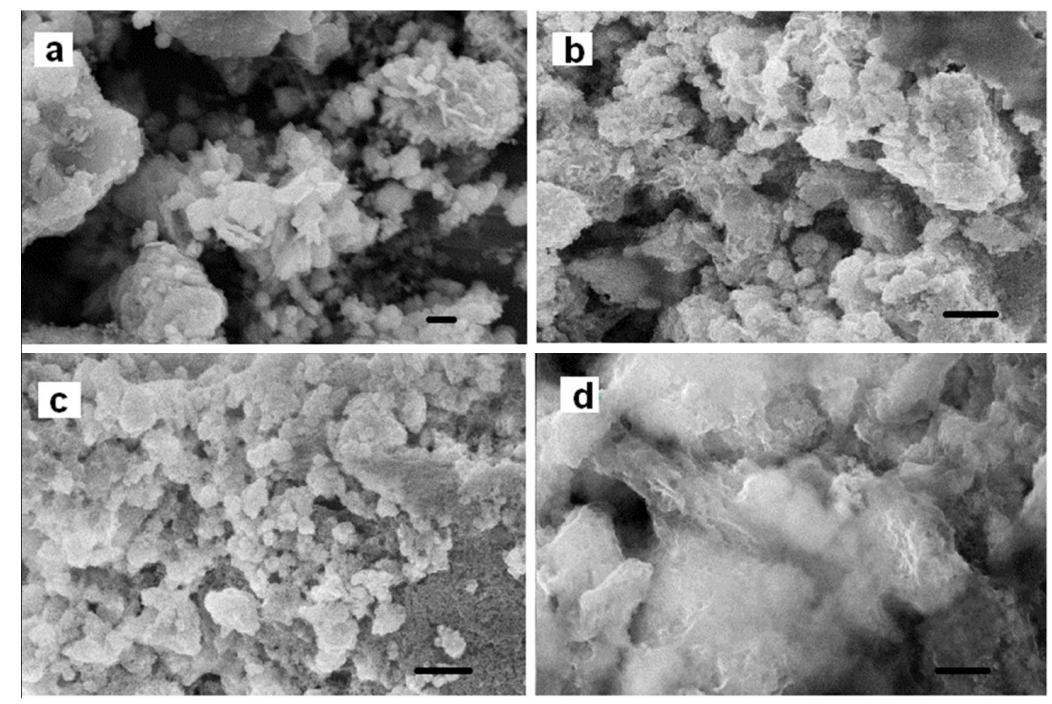

Figure 1. Scanning electron microscopy (SEM) micrographs of: (A) Sieved zero-valent iron (ZVI) sample; (B) Polyhydroxybutyrate (PHB)-ZVI complex with PHB/ZVI ratio 2:1 (w/w); (C) PHB-ZVI complex with PHB/ZVI ratio 1:1 (w/w); (D) PHB-ZVI complex with PHB/ZVI ratio 1:2 (w/w). Scale bars represent $200 \mathrm{~nm}$.

\subsection{FTIR Measurements}

FTIR was used in order to explore the coordination of the organic material to the ZVI in ZVI-PHB complexes (Figure 2). FTIR analysis of the uncoated ZVI displays a wide infrared undefined spectrum between 750 and $1800 \mathrm{~cm}^{-1}$. The PHB displays a peak at $1720 \mathrm{~cm}^{-1}$ that can be assigned to the carbonyl group in the polymer. FTIR spectra of the ZVI-PHB complexes present the same peaks found in the PHB spectrum, yet with a smaller intensity of the peaks. Chung and Lee [33] reported similar observations, in which they evidenced the disappearance of the - $\mathrm{COOH}$ and $-\mathrm{OH}$ stretch (close to $3030 \mathrm{~cm}^{-1}$ ), and $\mathrm{C}=\mathrm{O}$ strong stretch modes (around $1720 \mathrm{~cm}^{-1}$ ) after mercaptoacetic acid coating of $\mathrm{Ag}$ surfaces. In particular, in our data, the deficiency of a band representing carbonyl (close to $1720 \mathrm{~cm}^{-1}$ ) group indicates that a monolayer of PHB is adsorbed chiefly via carbonyl group on the metallic Fe. Therefore, FTIR analysis clearly indicated the efficiency of the procedure employed for the preparation of ZVI-PHB composites.

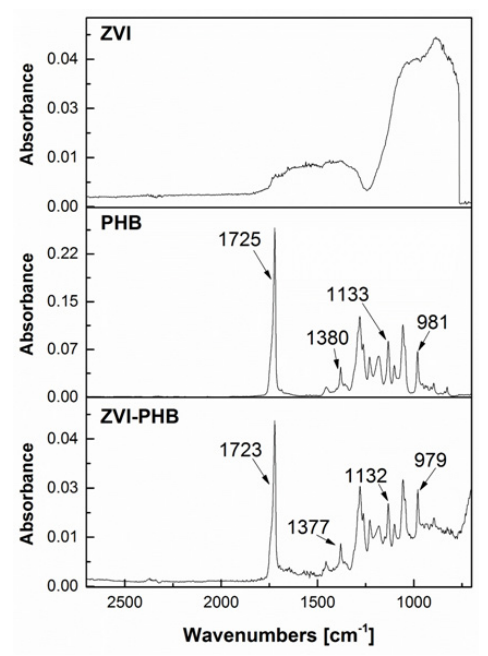

Figure 2. Fourier transform infrared spectroscopy (FTIR) measurements of bare ZVI, thermally treated $\mathrm{PHB}$, and ZVI-PHB composite (ZVI/PHB ratio 1:2 w/w). 


\subsection{Textural Analysis}

BET specific surface area and total pore volume values are reported in Table 1. The materials are mesoporous (Figure 3a) with a characteristic pore size (diameter) distribution in the range 20-500 (Figure $3 b$ ). Such a porosity is very modest, and is probably due to the characteristics of the commercial PHB starting material. The thermal treatment of PHB slightly decreases both the specific surface area and the total pore volume by decreasing the amount of pores, particularly those with diameter in the 20-200 A range. As far as the ZVI-PHB composite is concerned, it maintains the textural features of the treated PHB for porosity up to $40 \AA$ in diameter, and shows a slight increase in the amount of pores with size $>40 \AA$ A.

Table 1. Surface areas and total pore volumes of commercial untreated PHB (polyhydroxybutyrate), thermally treated PHB, and ZVI (zero-valent iron)-PHB composite (ZVI/PHB ratio 1:2 w/w).

\begin{tabular}{ccc}
\hline Sample & Surface Area $\left(\mathbf{m}^{2} / \mathbf{g}\right)$ & Total Pore Volume $\left(\mathbf{c m}^{3} / \mathbf{g}\right)$ \\
\hline Untreated PHB & $6.1 \pm 0.5$ & 0.0160 \\
Treated PHB & $3.5 \pm 0.5$ & 0.0095 \\
ZVI-PHB Composite & $4.3 \pm 0.5$ & 0.0162 \\
\hline
\end{tabular}
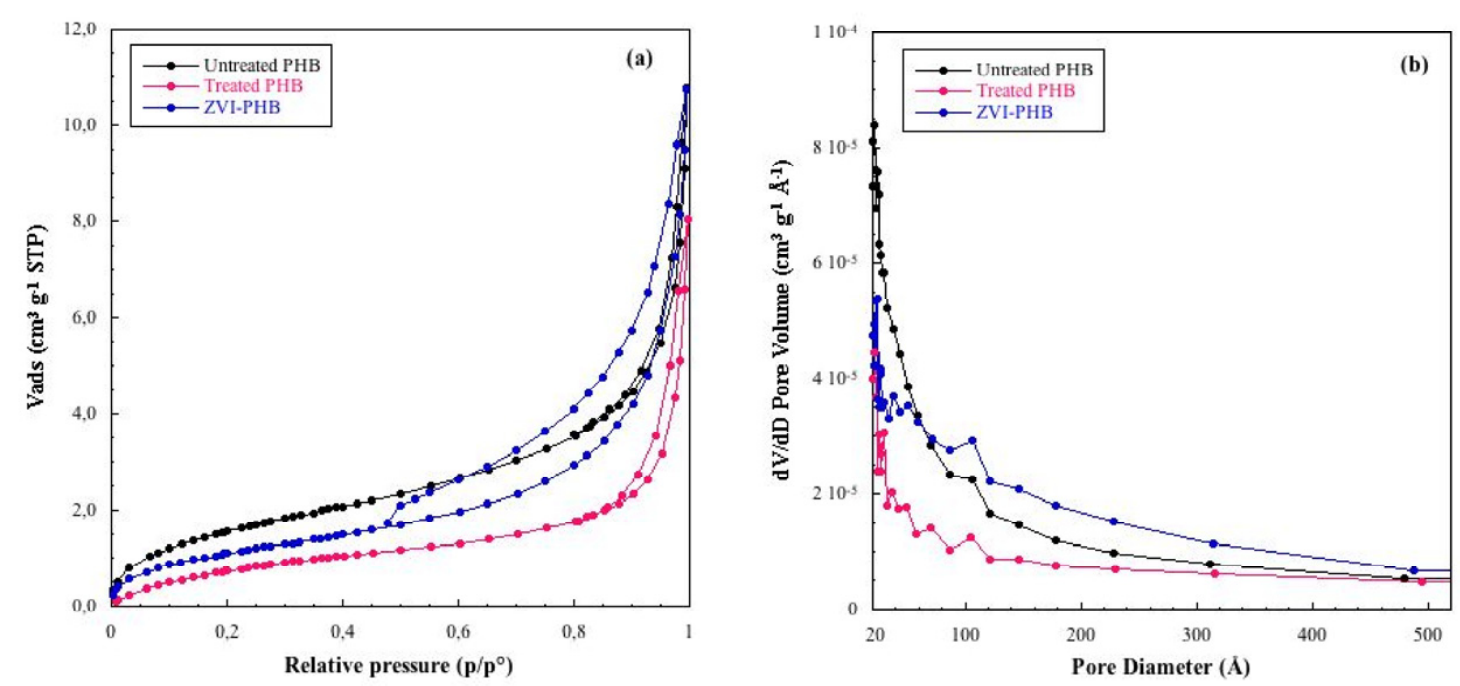

Figure 3. (a) $\mathrm{N}_{2}$ adsorption/desorption isotherms; and (b) pore size distribution of commercial untreated PHB, thermally treated PHB, and ZVI-PHB composite samples (ZVI/PHB ratio 1:2 w/w).

\subsection{TGA Measurements}

The TGA of PHB and ZVI-PHB composite demonstrated a loss of mass as a function of temperature (Figure 4). Figure 4 shows the thermal decay profiles of the PHB and ZVI-PHB complex. Rapid weight loss occurred after heating beyond $252{ }^{\circ} \mathrm{C}$, and the PHB seems to have decayed entirely once the temperature exceeded $294^{\circ} \mathrm{C}$. Then again, within the same temperature range, the ZVI-PHB complex lost approximately $50 \%$ of its initial mass. The remaining residue of the ZVI-PHB complex should be chiefly ascribed to the iron based species within the complex [29]. Therefore, according to the thermogravimetric analysis, $\sim 50 \%$ of the mass of ZVI-PHB composites is estimated to be made of ZVI particles. 


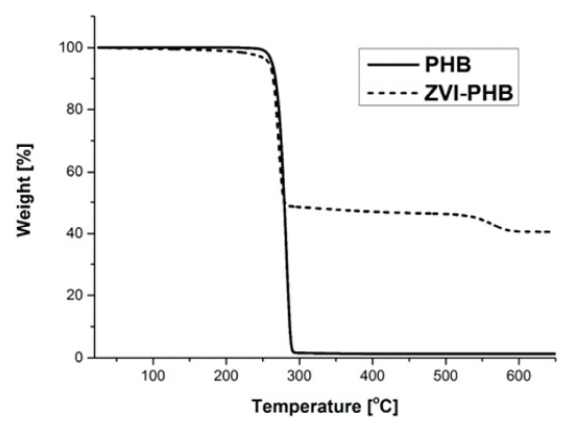

Figure 4. Thermogravimetric analysis (TGA) of thermally treated PHB and ZVI-PHB composite samples (ZVI/PHB ratio 1:2 w/w).

\subsection{Disc Centrifuge Analysis}

In our study, it was determined that $\sim 18 \%$ of the ZVI and ZVI-PHB composites belong to the small fraction. This translates to a large contribution of that fraction to the active surface area, which was determined to be $1.73 \mathrm{~m}^{2} / \mathrm{g}$ ( $49 \%$ of the entire surface area of ZVI-PHB). Particle size distributions of bare ZVI and ZVI-PHB complexes analyzed by CPS technique are presented in Figure 5 . The median particle number size distribution of bare ZVI particles within the range of $0.250 \mu \mathrm{m}$ to $5 \mu \mathrm{m}$ was found to be $0.44 \pm 0.01 \mu \mathrm{m}$. However, after PHB addition, the mean particle size of ZVI was determined to be $0.40 \pm 0.01 \mu \mathrm{m}$. Clearly, the particle size distribution of ZVI-PHB samples becomes sharper, and its mean size is smaller in comparison to the bare ZVI particles. In addition, the particle size measurements correspond with those evidenced by scanning electron microscopy (SEM) analysis (Figure 1).

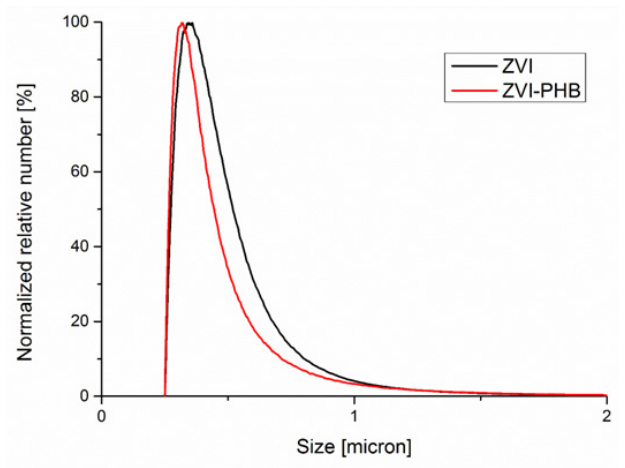

Figure 5. Particle size distribution of bare ZVI and ZVI-PHB composite samples (ZVI/PHB ratio 1:2 w/w).

\subsection{Zeta Potential Measurements}

The increased stability of the PHB-stabilized ZVI particles was additionally characterized by studying the changes in surface potential. In practice, the electric potential near the surface of the molecule (i.e., $\zeta$-potential) is oftentimes assessed and applied as an indicator of the surface potential. The $\zeta$-potential values for ZVI and ZVI-PHB particles at $\mathrm{pH} 7$ were found to be $-0.03 \pm 0.1 \mathrm{mV}$ and $18.73 \pm 0.5 \mathrm{mV}$, respectively. The magnitude of the surface potential generally regulates the degree of the electrostatic repulsion between molecules. The ZVI particles were slightly negative at $\mathrm{pH} 7$. After PHB addition, the $\zeta$-potential increased to $18.73 \mathrm{mV}$, which could significantly increase the repulsion between the particles. Increasing the $\zeta$-potential can enhance the electrostatic repulsion among particles, thereby stabilizing the suspension.

\section{Conclusions}

In this work, we employed an operatively simple yet effective procedure based on the precipitation of PHB from an organic phase in the presence of an aqueous dispersion of ZVI in order to prepare 
composite materials suitable for advanced bioremediation applications. The materials employed are commercially available at a low-cost, combining the well-known reducing properties of ZVI towards chlorinated pollutants and a slow-releasing carbon source such as PHB. Experimental data indicate that a monolayer of the polymer was adsorbed on the Fe metallic surface, with a final ratio between the two components in the ZVI-PHB composite of approximately 1:1. This interaction was able to increase the stability of ZVI particles, as evidenced by zeta-potential measurements and disc centrifuge analysis. The accurate chemico-physical characterization of the ZVI-PHB composites described in this study is of fundamental importance and preliminary to successive studies that will explore their application in the treatment of chlorinated solvent-contaminated aquifers. The ZVI-PHB composites described in this work appear to be particularly promising materials for enhancing the performance of PRBs towards chlorinated compounds.

Acknowledgments: The authors would like to acknowledge financial support from Università degli Studi di Roma "La Sapienza", Grandi Progetti Universitari Anno 2015, "Development and characterization of reactive materials for groundwater remediation", as well as the Czech Ministry of Education, Youth and Sports in the framework of the projects: the National Programme for Sustainability I (LO1201), Research Infrastructure NanoEnviCz (LM2015073), the OPR \& DI (operational program research and development for innovations) project "Institute for Nanomaterials, Advanced Technologies and Innovation", CZ.1.05/2.1.00/01.0005 and the Competence Centre of the Technology Agency of the Czech Republic (TE01020218).

Author Contributions: M.P.P. and C.P. conceived and designed the experiments; L.C., I.P. and S.W. performed the experiments; L.C., S.W., F.V. and M.C. analyzed the data; L.C. and S.W. wrote the paper.

Conflicts of Interest: The authors declare no conflict of interest.

\section{References}

1. Lapworth, D.J.; Baran, N.; Stuart, M.E.; Ward, R.S. Emerging organic contaminants in groundwater: A review of sources, fate and occurrence. Environ. Pollut. 2012, 163, 287-303. [CrossRef] [PubMed]

2. Jones, K.C. Organic Contaminants in the Environment: Environmental Pathways \& Effects; Elsevier Science Publishers Ltd.: Barking, UK, 2013.

3. Directive 2006/118/EC of the European Parliament and of the Council of 12 December 2006 on the Protection of Groundwater against Pollution and Deterioration. Available online: http://eur-lex.europa.eu/legalcontent/EN/TXT/?uri=uriserv\%3AOJ.L_.2014.182.01.0052.01.ENG (accessed on 28 September 2016).

4. Mackay, D.M.; Cherry, J.A. Groundwater contamination: Pump-and-treat remediation. Environ. Sci. Technol. 1989, 23, 630-636. [CrossRef]

5. Park, D.K.; Ko, N.; Lee, K. Optimal groundwater remediation design considering effects of natural attenuation processes: Pumping strategy with enhanced-natural-attenuation. Geosci. J. 2007, 11, 377-385. [CrossRef]

6. Park, Y.; Jeong, J.; Eom, S.; Jeong, U.P. Optimal management design of a pump and treat system at the industrial complex in Wonju, Korea. Geosci. J. 2011, 15, 207-223. [CrossRef]

7. Thiruvenkatachari, R.; Vigneswaran, S.; Naidu, R. Permeable reactive barrier for groundwater remediation. J. Ind. Eng. Chem. 2008, 14, 145-156. [CrossRef]

8. Obiri-Nyarko, F.; Grajales-Mesa, S.J.; Malina, G. An overview of permeable reactive barriers for in situ sustainable groundwater remediation. Chemosphere 2014, 111, 243-259. [CrossRef] [PubMed]

9. Scherer, M.M.; Richter, S.; Valentine, R.L.; Alvarez, P.J.J. Chemistry and Microbiology of Permeable Reactive Barriers for In Situ Groundwater Clean up. Crit. Rev. Microbiol. 2000, 26, 221-264. [CrossRef] [PubMed]

10. Statham, T.M.; Stark, S.C.; Snape, I.; Stevens, G.W.; Mumfor, K.A. A permeable reactive barrier (PRB) media sequence for the remediation of heavy metal and hydrocarbon contaminated water: A field assessment at Casey Station, Antarctica. Chemosphere 2016, 147, 368-375. [CrossRef] [PubMed]

11. Chung, H.I.; Kim, S.K.; Lee, Y.S.; Yu, J. Permeable reactive barrier using atomized slag material for treatment of contaminants from landfills. Geosci. J. 2007, 11, 137-145. [CrossRef]

12. Moraci, N.; Calabrò, P.S. Heavy metals removal and hydraulic performance in zero-valent iron/pumice permeable reactive barriers. J. Environ. Manag. 2010, 91, 2336-2341. [CrossRef] [PubMed]

13. Matheson, L.J.; Tratnyek, P.G. Reductive Dehalogenation of Chlorinated Methanes by Iron Metal. Environ. Sci. Technol. 1994, 28, 2045-2053. [CrossRef] [PubMed] 
14. Roberts, A.L.; Totten, L.A.; Arnold, W.A.; Burris, D.R.; Campbell, T.J. Reductive Elimination of Chlorinated Ethylenes by Zero-Valent Metals. Environ. Sci. Technol. 1996, 30, 2654-2659. [CrossRef]

15. Reardon, E.J. Zerovalent Irons: Styles of Corrosion and Inorganic Control on Hydrogen Pressure Buildup. Environ. Sci. Technol. 2005, 39, 7311-7317. [CrossRef] [PubMed]

16. Li, S.; Ding, Y.; Wang, W.; Lei, H. A facile method for determining the $\mathrm{Fe}(0)$ content and reactivity of zero valent iron. Anal. Methods 2016, 8, 1239-1248. [CrossRef]

17. Kim, H.; Yang, H.; Kim, J. Standardization of the reducing power of zero-valent iron using iodine. J. Environ. Sci. Heal. A 2014, 49, 514-523. [CrossRef] [PubMed]

18. Btatkeu, B.D.; Miyajima, K.; Noubactep, C.; Caré, S. Testing the suitability of metallic iron for environmental remediation: Discoloration of methylene blue in column studies. Chem. Eng. J. 2013, 215, 959-968. [CrossRef]

19. Lojkasek-Lima, P.; Aravena, R.; Shouakar-Stash, O.; Frape, S.K.; Marchesi, M.; Fiorenza, S.; Vogan, J. Evaluating TCE abiotic and biotic degradation pathways in a permeable reactive barrier using compound specific isotope analysis. Ground Water Monit. R. 2012, 32, 53-62. [CrossRef]

20. Wilkin, R.T.; Acree, S.D.; Ross, R.R.; Puls, R.W.; Lee, T.R.; Woods, L.L. Fifteen-year assessment of a permeable reactive barrier for treatment of chromate and trichloroethylene in groundwater. Sci. Total Environ. 2014, 468, 186-194. [CrossRef] [PubMed]

21. Chen, L.; Jin, S.; Fallgren, P.H.; Swoboda-Colberg, N.G.; Liu, F.; Colberg, P.J. Electrochemical depassivation of zero-valent iron for trichloroethene reduction. J. Hazard. Mater. 2012, 239, 265-269. [CrossRef] [PubMed]

22. Song, H.; Carraway, E.R. Reduction of chlorinated ethanes by nanosized zero-valent iron: Kinetics, pathways, and effects of reaction conditions. Environ. Sci. Technol. 2005, 39, 6237-6245. [CrossRef] [PubMed]

23. Arjoon, A.; Olaniran, A.O.; Pillay, B. Enhanced 1,2-dichloroethane degradation in heavy metal co-contaminated wastewater undergoing biostimulation and bioaugmentation. Chemosphere 2013, 93, 1826-1834. [CrossRef] [PubMed]

24. He, F.; Zhao, D. Preparation and Characterization of a New Class of Starch-Stabilized Bimetallic Nanoparticles for Degradation of Chlorinated Hydrocarbons in Water. Environ. Sci. Technol. 2005, 39, 3314-3320. [CrossRef] [PubMed]

25. Krol, M.M.; Oleniuk, A.J.; Kocur, C.M.; Sleep, B.E.; Bennett, P.; Xiong, Z.; O'Carroll, D.M. A Field-Validated Model for In Situ Transport of Polymer-Stabilized nZVI and Implications for Subsurface Injection. Environ. Sci. Technol. 2013, 47, 7332-7340. [CrossRef] [PubMed]

26. Gastone, F.; Tosco, T.; Sethi, R. Green stabilization of microscale iron particles using guar gum: Bulk rheology, sedimentation rate and enzymatic degradation. J. Colloid Interface Sci. 2014, 421, 33-43. [CrossRef] [PubMed]

27. Velimirovic, M.; Simons, Q.; Bastiaens, L. Guar gum coupled microscale ZVI for in situ treatment of CAHs: Continuous-flow column study. J. Hazard. Mater. 2014, 265, 20-29. [CrossRef] [PubMed]

28. Villano, M.; Valentino, F.; Barbetta, A.; Martino, L.; Scandola, M.; Majone, M. Polyhydroxyalkanoates production with mixed microbial cultures: From culture selection to polymer recovery in a high-rate continuous process. N Biotechnol. 2014, 31, 289-296. [CrossRef] [PubMed]

29. Wacławek, S.; Chronopoulou, L.; Petrangeli Papini, M.; Vinod, V.T.P.; Palocci, C.; Kupčík, J.; Černík, M. Enhancement of stability and reactivity of nanosized zero-valent iron with polyhydroxybutyrate. Desalin. Water Treat. 2016. [CrossRef]

30. Baric, M.; Majone, M.; Beccari, M.; Petrangeli Papini, M. Coupling of polyhydroxybutyrate (PHB) and zero valent iron (ZVI) for enhanced treatment of chlorinated ethanes in permeable reactive barriers (PRBs). Chem. Eng. J. 2012, 195-196, 22-30. [CrossRef]

31. Gregg, S.J.; Sing, K.S.W. Adsorption, Surface Area and Porosity, 2nd ed.; Academic Press Inc.: London, UK, 1982.

32. Barrett, E.P.; Joyner, L.G.; Halenda, P.P. The Determination of Pore Volume and Area Distributions in Porous Substances. I. Computations from Nitrogen Isotherms. J. Am. Chem. Soc. 1951, 73, 373-380. [CrossRef]

33. Chung, C.; Lee, M. Self-Assembled Monolayers of Mercaptoacetic Acid on Ag Powder: Characterization by FT-IR Diffuse Reflection Spectroscopy. Bull. Korean Chem. Soc. 2004, 25, 1461-1462.

(C) 2016 by the authors; licensee MDPI, Basel, Switzerland. This article is an open access article distributed under the terms and conditions of the Creative Commons Attribution (CC-BY) license (http://creativecommons.org/licenses/by/4.0/). 